\title{
Test Anxiety Inventory (TAI): Factor Analysis and Psychometric Properties
}

\author{
Muhammad Shabbir Ali ${ }^{1}$, Muhammad Naeem Mohsin ${ }^{2}$ \\ 1. Assistant Professor (Ph. D. Education), GC University Faisalabad, Pakistan \\ 2. Director Distance Learning Education, GC University Faisalabad, Pakistan
}

\begin{abstract}
The aim of this study was to examine factor structure and explore the psychometric properties for Urdu version of Test Anxiety Inventory. 2,145 secondary and higher secondary science students were selected as sample from the Punjab province in Pakistan appearing in $10^{\text {th }}$ grade Board examinations. The value of alpha reliability for TAI was .893 in the pilot study. But in the final study, alpha reliability values for different scales of TAI (TAI-Total, TAI-Worry, and TAI-Emotionality) ranged from 0.66 to 0.81 with the individual student as the unit of analysis and from 0.71 to 0.88 with the class as the unit of analysis. Similarly, The discriminant validity of an individual student as unit of analysis ranged from 0.19 to 0.32 for three scales of TAI, while the discriminant validity for class as unit of analysis ranged from 0.27 to 0.40 for these scales of TAI. A three-factor structure consisting of TAI-Total, TAI-worry and TAI-Emotionality components showed acceptable discriminant validity and internal reliability.
\end{abstract}

Key Words: Anxiety, Test Anxiety, Psychometric properties, Factor analysis, Test Anxiety Inventory (TAI)

\section{Introduction}

Phillips, Martin, and Myers (1972) have described that anxiety is a response to different environmental factors ${ }^{\mid 1 !}$. According to Sarason (1984), anxiety directly belongs to the emotions of human beings and it points out the lack of self-assurance. It may also be a kind of threat from the environment. He has also stated that anxiety is the most important factor in all fields of studies as well as researched in many studies and countries ${ }^{21 .}$

The term anxiety has been described by Cohen, Yaakobi, Porat, and Chayoth (1989) as the emotional state which is expressed by psychological and physiological phenomena. It can be generalized that anxiety has negative effects on students' self-esteem. The students can learn from their own experiences about the stimuli which cause anxiety. But these stimuli vary from person to person as no two persons have same ideas and thoughts ${ }^{|3|}$. In the view point of Reber (1995), anxiety is an emotional state in unpleasant conditions without a specific object ${ }^{|4|}$.

Lufi, Okasha, and Cohen (2004) have divided anxiety into two categories: state anxiety and trait anxiety. The trait anxiety is described as the individual's capability to perceive different situations from the environment like danger and threat. On the other hand, state anxiety is described as the perception of individual's emotional situation $|5|$. According to Spielberger (1979), the term state anxiety expresses the emotional situations of the individuals which consist of feelings of tension, apprehension, nervousness and worry $|6|$.

\section{Test Anxiety}

Most students have to face different situations of anxiety during the examination. In the viewpoint of Sarason and Stoops (1978), anxiety has adverse and negative effects in the process of examination. It is not necessary that students, who get lower achievement in the examinations, are less intelligent. It may be the result of test anxiety ${ }^{|7|}$. Test anxiety is defined by Duesek (1980) as "An emotional state that has psychological and behavioral concomitants, and that is experienced in formal testing or other evaluative situations" (p. 88) ${ }^{|8|}$.

Sarason (1984) refers to test anxiety as "A widely studied personality variable in part because it provides a measure of the personal salience of one important definable class of threating situations in which people are evaluated" (p. 292) ${ }^{|9|}$. According to Liepmann, Marggraf, Felfe, and Hosemann (1992), test anxiety is always developed among students due to results of failure, and it is communicated through early interactions of judgments of parents of those students who are performing in the tests ${ }^{|10|}$. Spielberger and Vagg (1995) have described that test anxiety is an element of general anxiety. According to them, "test anxiety is composed of cognitive attention processes that interfere with performance in academic situations or examinations." |11|

A very important definition of test anxiety is given by Zeidner (1998), "The set of phenomenological, physiological and behavioral responses that accompany concern about possible negative consequences or failure on the examination or similar evaluative situation" (p. 17) ${ }^{|12|}$. On the other hand, Hong (1998) has given the 
definition of test anxiety as "complexes multidimensional construct involving cognitive, physiological, and behavioral reactions to evaluative situations" (p. 51) ${ }^{|13|}$.

\subsection{Concepts of Test Anxiety}

Spielberger (1980) has described three different concepts of test anxiety which are personality trait, emotional state and clinical state. When it is considered a personality trait, it is assumed that the tests are perceived as threatening ${ }^{|14|}$. Zeidner (1998) has explained the emotional state. It is a degree of anxiety immediately faced by students in a particular test situation ${ }^{|12|}$. Sapp, Durand, and Farrel (1995) have given the concept of test anxiety as ".......special case of a general anxiety disorder related to taking examination" $|15|$. This definition explains the third concept of test anxiety which is clinical state or disorder.

\subsection{Components of Test Anxiety}

According to Liebert and Morris (1969) there are two components of test anxiety i.e., worry and emotionality ${ }^{|16|}$. But according to Sarason (1984), there are four components of test anxiety: worry, testirrelevant thinking, tension and bodily symptoms ${ }^{|9|}$. Unruh and Lowe (2010) have also mentioned four components of test anxiety which are worry, cognitive interference, emotionality and lack of self-confidence. But worry and emotionality are the major components of test anxiety ${ }^{1171}$.

According to Morris, Davis, and Hutchings (1981), test anxiety is a broader concept and differences in Worry and Emotionality as components of test anxiety have made many developments in this field ${ }^{|18|}$. Sharma and Sud (1990) have explained that 'Worry' is a cognitive component which concerns about one's achievement for the consequences of failure. On the other hand, 'Emotionality' is a self-perceived arousal or the reactions of autonomic nervous system ${ }^{|19|}$. Similarly, Lufi et al. (2004) have distinguished between worry and emotionality. Worry is cognitive distress which has effects on tests while emotionality is the affective distress on physical reactions as fear of tests ${ }^{|5|}$.

\section{The Measurement of Test Anxiety}

The researchers have developed several instruments for the measurement of test anxiety. Some of these instruments are briefly described below:

\section{1) Test Anxiety Questionnaire (TAQ)}

The first instrument to measure test anxiety was Test Anxiety Questionnaire (Mandler and Sarason, 1952)

${ }^{120 \mid}$. It contains 42 items measuring students' own experiences before and during the examinations. The numbers of items in this questionnaire are 36 . The students have to respond to all the items by placing a mark along a 15 centimeter line which is indicated by the midpoint and the endpoint.

2) Test Anxiety Scale (TAS)

Srason (1958) constructed the Test Anxiety Scale (TAS) consisting of 21 items. The students have to respond to the items by circling true and false ${ }^{|21|}$.

3) Achievement Anxiety Test (AAT)

The Achievement Anxiety Test (AAT) was developed by Alpert and Haber (1960) to measure test anxiety of students ${ }^{122}$. This instrument consists of 2 scales and 28 items. These scales are: a 10-item Debilitating Scale (AAT-) and a 9-item Facilitating Scale (AAT+). The remaining 9-items are neutral. The subjects have to respond on a 5-point scale.

4) Suinn Test Anxiety Behavior Scale (STABS)

This instrument was constructed by Suinn (1969) ${ }^{23 \mid}$. It consists of 50 items. The behavioral situations, which can cause test anxiety, are described in these items. Students have to respond to these 50 items on a 5-point scale.

5) Worry-Emotionality Questionnaire (W-E Q)

Liebert and Morris (1969) developed the Worry-Emotionality Questionnaire (W-E Q) ${ }^{|16|}$. This instrument consists of 10 items which have been modified for the immediate feelings and responses of the students. This instrument contains 5-items for Worry Scale and 5-items for Emotionality Scale.

6) Inventory of Test Anxiety (ITA)

The Inventory of Test Anxiety (ITA) was developed by Osterhouse (1970) ${ }^{\mid 24}$. It contains two subscales with 16 items: the Worry and Emotionality Subscales. Each scale is composed of 8 items.

7) State Test Anxiety Scale (STAS)

This scale was developed by Hong (1998) ${ }^{|13|}$. It consists of Worry and Emotionality Subscales. Both of these subscales require responses on a 4-point Likert-type scale. The range of score is from 4 to 16 . The cognitive component of anxiety is Worry Subscale and physiological component is Emotionality Subscale in this instrument. 


\section{8) Test Anxiety Inventory for Children and Adolescents (TAICA)}

Lowe and Lee (2004) constructed this instrument for the measurement of test anxiety of elementary and secondary students through grades $4-12^{|25|}$. It consists of 45 items and six scales. These six scales are Cognitive Obstruction, Physiological Hperarousal, Social Humiliation, Worry, Performance Enhancement and a Lie Scale.

9) Test Anxiety Inventory (TAI)

Test Anxiety Inventory was developed by Spielberger (1980) ${ }^{|14|}$. It consists of 20 items. According to Chapell, Blanding, Silverstein, Takahashi, Newman, Gubi, and McCann (2005), the Test Anxiety Inventory is the most important and widely used instrument for the measurement of high school and college students' test anxiety ${ }^{|26|}$.

Spielberger's Test Anxiety Inventory (1980) is a self-report instrument consisting of 20 items ${ }^{|14|}$. According to Spielberger, Gonzalez, Taylor, Algaze, and Anton (1978), the development of TAI was based on two goals. These goals were construction of a brief and self-report scale and the employment of factor analytic procedures for the measurement of Worry and Emotionality Subscales ${ }^{|27|}$.

According to Spielberger (1980), Test Anxiety Inventory is especially designed to measure the test anxiety of high school and college students. It contains three subscales: Test Anxiety-Total (TAI-T), Test Anxiety-Worry (TAI-W), and Test Anxiety-Emotionality (TAI-E). Eight items of Test Anxiety Inventory measure the TAI-W, eight items measure TAI-E and the remaining four for measuring TAI-T. Test Anxiety Inventory is a 4-point Likert type scale and the students have to respond to the four options: (1) Almost Never, (2) Sometimes, (3) Often and (4) Almost Always. The reliability values of alpha coefficient for subscales of original version of Test Anxiety Inventory were: 0.96 for TAI-T, 0.91 for TAI-W and 0.91 for TAI-E ${ }^{|14|}$

\section{Review of Research Studies using Test Anxiety Inventory}

Many research studies have been conducted in different countries using the Test Anxiety Inventory (Spielberger, 1980) ${ }^{|14|}$. This part of the chapter reviews some of research studies in which Test Anxiety Inventory is used.

Schwarzer (1980) ${ }^{|28|}$ conducted a longitudinal study on students of grade 6 and 9 to investigate Worry and Emotionality Subscales using Test Anxiety Inventory. Confirmatory factor analysis (Bentler, 1980) ${ }^{|29|}$ was used for data analysis. The two factors worry and emotionality were correlated (.67 in the female sample and .54 in the male sample). Item analysis was also performed for internal consistencies of Emotionality Subscale (.91 for girls, .86 for boys) and Worry Subscale (.75 for girls, .71 for boys).

Anthony, Devito, Tryon, and Kane (1983) collected data from 233 female and 292 male students by using the Test Anxiety Inventory. The significant level .02 was adapted rather than $.05^{|30|}$ In another study by McAuliffe and Trueblood (1986), Test Anxiety Inventory was used to measure the relationship of Mathematics Anxiety Rating Scale (MARS) with both the factors of Worry and Emotionality of Test Anxiety Inventory. The data was collected from 138 pre-service elementary and special education teachers. The two factors of Test Anxiety Inventory: Worry and Emotionality were used ${ }^{|31|}$.

Rocklin (1989) conducted a research study on individual differences in computerized self-adapted testing by using Test Anxiety Inventory from 29 college students ${ }^{32 \mid}$. Test Anxiety Inventory was also used by Wynstra and Cummings (1990) to find out the relationships of science anxiety, test anxiety, and achievement in science. Test Anxiety Inventory was used to measure test anxiety of $10^{\text {th }}$ grade through $12^{\text {th }}$ grade students of chemistry class ${ }^{133 \mid}$. Similarly, Sharma and Sud (1990) used nine different versions of Test Anxiety Inventory in nine different languages including English version. The data was collected from 7,679 male and female students selected from an urban high school. All the subscales i.e., TAI-Total, TAI-Worry and TAI-Emotionality of Test Anxiety Inventory were used in this study ${ }^{|19|}$.

Williams (1992) assessed the effects of test anxiety and self-concept on performance by using Test Anxiety Inventory to measure the test anxiety. A sample of 217 students was selected from a high school ${ }^{\square} \square$. In another study, Calvo and Carreiras $(1993)^{|35|}$ administered Test Anxiety Inventory. 36 psychology undergraduate students were selected as a sample. Firstly, these 36 students were administered Test Anxiety Inventory to measure their trait test anxiety. Secondly, they were administered State-Trait Anxiety Inventory (Spielberger and Dlaz-Guerroro, $1975^{|36|}$ ) to measure their state anxiety.

Stallworth-Clark, Cochran, and Scott (1998) administered the Test Anxiety Inventory as pre- and posttest in their study. 37 male and 42 female students completed Test Anxiety Inventory as pre-test. Then after experiment, 30 male and 40 female students completed Test Anxiety Inventory as post-test. The results of the study supported the findings of Test Anxiety Inventory authors that Test Anxiety Inventory total scores for female students were 3 to 5 points higher than those of male students in four norming samples ${ }^{|37|}$. On the other hand Shermis and Lombard (1998) conducted a research study to examine the effect of test anxiety on students' performance. The data was collected from 72 undergraduate college students by administering Test Anxiety 
Inventory. The students were 52 females and 20 males and their ages ranged from 18 to 50 years. The mean Test Anxiety Inventory scores for males were $39.55(\mathrm{SD}=13.35)$ and for females were $41.14(\mathrm{SD}=13.35)^{|38|}$.

In a research study on test anxiety, perceived test anxiety, and test performance, Hong (1999) used Test Anxiety Inventory as test anxiety instrument. The data was collected from 208 undergraduate students, before and after their final examinations. Eight items of Test Anxiety Inventory were used: four items for Worry and four for Emotionality Subscales. The internal consistencies before the examination for Worry and Emotionality Subscales were .80 and .91 , respectively. Similarly, internal consistencies after the examination were .88 and .93 , respectively $|39|$.

Maxfield and Melnyk (2000) used Test Anxiety Inventory in their research study conducted on 44 second year psychology students. The mean scores for Test Anxiety Inventory total were $58.5^{|40|}$. Similarly, in another study, Kaya (2004) collected data from fifth-grade Turkish students at elementary level by administering Test Anxiety Inventory ${ }^{41 \mid}$. In another study, Lufi et al. (2004) used Test Anxiety Inventory while conducting their research on Israeli students. Test Anxiety Inventory was administered among 54 Israeli students. The Test Anxiety Inventory used in this study was translated into Hebrew ${ }^{|5|}$. Similarly, Lufi and Darliuk (2005) administered Test Anxiety Inventory among 166 students aged 14-18 years. The value of alpha coefficient for this translated version was 0.92 for TAI-Total, 0.88 for TAI-Emotionality and 0.84 for TAIWorry ${ }^{|42|}$.

Putwain (2007) conducted a study to collect some exploratory data regarding test anxiety scores by using Test Anxiety Inventory. The data was collected from a sample of 1,348 students (690 in the year 10 and 658 in the year 11). These students were selected from seven secondary schools in the north of UK. The factor analysis of the Test Anxiety Inventory was examined using multiple regression analysis ${ }^{|43|}$. Likewise, Putwain (2008) also used Test Anxiety Inventory in another research study on test anxiety and performance by collecting data from a sample of 558 students selected from three schools ${ }^{|4|}$.

Nicholson (2010) administered Test Anxiety Inventory in his research study to determine the effects of test anxiety on students' achievement. 200 eleventh grade students from high school were selected as sample. Multiple regressions were used for data analysis ${ }^{|45|}$.

In a research study Ali (2012) administered Test Anxiety Inventory on 1,845 secondary school science students to measure their test anxiety. This instrument was first translated into Urdu language and then it was standardized. The two factor structure comprising of worry and emotionality subscales showed acceptable construct validity and reliability ${ }^{466 !}$.

\section{Aims of this study}

The aims of this study were: (1) to translate Test Anxiety Inventory into Urdu language, (2) to examine factor structure for Urdu version of Test Anxiety Inventory, and (3) to explore its psychometric properties when administered on secondary and higher secondary school science students in Punjab province.

\subsection{Participants}

\section{Methodology}

Data was collected from 2,145 secondary and higher secondary school science students drawn from forty six schools located in five districts from the Punjab province of Pakistan. This data was collected from urban $(n=1280)$ and rural $(n=865)$ areas. These participants were studying in $10^{\text {th }}$ grade board examinations taking physics, chemistry, mathematics, biology and computer science as science subjects.

\subsection{Instrument}

In the present study, the Urdu translation of the Test Anxiety Inventory (TAI) was used. Although the Urdu translation of Test Anxiety Inventory was already used by Ali $(2012)^{|46|}$ but low factor loadings were reported for some items. Then Test Anxiety Inventory was again translated into Urdu language by five experts of language. These translations were compared and new Urdu translated version of Test Anxiety Inventory was developed.

\subsection{Pilot Testing for Urdu version of Test Anxiety Inventory}

The Urdu translated version of Test Anxiety Inventory was administered and pilot tested in this study on 220 tenth grade science students of public secondary and higher secondary schools selected from different schools in Punjab province. These students were studying Physics, Chemistry, Biology, Mathematics, and Computer Science as science subjects.

The students selected as sample for pilot study were asked to fill the Urdu translated version of Test Anxiety Inventory. For pilot testing, the reliability coefficient of Test Anxiety Inventory (TAI) was determined by calculating Cronbach Alpha Reliability Coefficient. This value was found $\alpha=.893$.

Table 1 below shows the mean, standard deviation, and reliability coefficient values of the pilot test. 
Table 1

Mean, Standard Deviation, and Reliability Coefficient on Test Anxiety Inventory (TAI)

\begin{tabular}{ccc}
\hline Mean & Standard Deviation & $\begin{array}{c}\text { Cronbach Alpha Reliability } \\
\text { Coefficient }\end{array}$ \\
\hline 42.5906 & 10.0854 & .893 \\
\hline
\end{tabular}

The reliability coefficients were also calculated for each subscale of Test Anxiety Inventory (TAI) which are given in Table 2 as below:

Table 2

Reliability Coefficients for Subscales of Test Anxiety Inventory (TAI)

\begin{tabular}{lcc}
\multicolumn{1}{c}{ TAI } & Number of Statements & $\begin{array}{c}\text { Alpha Reliability } \\
\text { Coefficient }\end{array}$ \\
\hline TAI-Worry & 8 & 0.743 \\
TAI-Emotionality & 8 & 0.899 \\
TAI-Total & 4 & 0.818 \\
\hline
\end{tabular}

Item analysis was performed after pilot testing. Dunn-Rankin $(1983)^{|47|}$ has described the procedure of item analysis as:

"The mean score of each individual item represents item difficulty for the particular item. The pearson ' $r$ ' of each item with the total score on all items (referred as Item-to-Total Correlation) act as a discrimination index for each item. If the item correlates highly with the total score, it is internally consistent and it should be retained. If a zero or very low correlation coefficient is obtained, it is not discriminating between groups and should be deleted."

Table 3 below represents the item statistics and the values of discrimination index for the questionnaire of Test Anxiety Inventory (TAI).

Table 3

Item Statistics and Item-Total Correlations

\begin{tabular}{ccc}
\hline Item Number & $\begin{array}{c}\text { Mean } \\
\text { (Difficulty Index) }\end{array}$ & $\begin{array}{c}\text { Item-Total } \\
\text { Correlation } \\
\text { (Discrimination } \\
\text { Index) }\end{array}$ \\
\hline TA 1 & 2.79 & 0.387 \\
TA 2 & 2.25 & 0.463 \\
TA 3 & 2.17 & 0.420 \\
TA 4 & 3.58 & 0.388 \\
TA 5 & 1.76 & 0.323 \\
TA 6 & 2.83 & 0.381 \\
TA 7 & 2.79 & 0.406 \\
TA 8 & 2.29 & 0.604 \\
TA 9 & 2.29 & 0.531 \\
TA 10 & 2.25 & 0.511 \\
TA 11 & 2.17 & 0.458 \\
TA 12 & 3.49 & 0.466 \\
TA 13 & 2.21 & 0.308 \\
TA 14 & 2.51 & 0.429 \\
TA15 15 & 0.651 \\
TA 16 & 2.29 & 0.590 \\
TA 17 & 2.41 & 0.312 \\
TA 18 & 2.56 & 0.393 \\
TA19 & 2.89 & 0.446 \\
TA 20 & 2.25 & 0.497 \\
\hline
\end{tabular}

On the basis of values given in Table 3, none of the item was rejected or deleted from the Test Anxiety Inventory. All 20 items were retained in the final questionnaire. 


\subsection{Data Collection for the Final Study}

The Urdu translated version of Test Anxiety Inventory was field tested and the data was collected from a sample of 2,145 science students selected from 30 public secondary and 16 higher secondary schools. These schools were selected from different areas in Punjab province. These students were studying Physics, Chemistry, Biology, Mathematics, and Computer Science as science subjects and they were asked to fill the Urdu translated version of Test Anxiety Inventory.

\subsection{Data Analysis}

The data collected from 2,145 science students was analyzed by Statistical Package for Social Sciences (SPSS) version 17 to examine the factor structure and explore the psychometric properties of Urdu version of Test Anxiety Inventory.

\subsection{Factor Analysis}

Factor analyses were conducted for the examination of internal structures of 20 items of Test Anxiety Inventory (TAI). According to Nunnally and Bernstein (1994), factor structure is very important tool to measure the psychological constructs ${ }^{148 \mid}$. According to Zaman (2011), a Kaiser Eigenvalue criterion decides to choose the factors ${ }^{\square 9}$. According to Kaiser (1960) Eigenvalue rule, only factors that have Eigenvalues greater than one are retained for interpretations ${ }^{|50|}$.

Keeping in view the above discussion, the internal structure of TAI was examined by using the principal axis factor analysis with Varimax rotation. The factor loadings obtained are described in Table 4. Factor loadings of 0.30 or higher are expressed in this table. The criterion for an item to be retained is described by Nelson (2005) ${ }^{|51|}$. According to this criterion, only that item is retained in an instrument whose factor loading is at least 0.30 on its own scale and less than 0.30 on all other scales. By following this criterion, none of the items were deleted from TAI and all 20 items retained in TAI after factor analysis.

Table 4 below presents the factor loadings, percentage of variance, and eigenvalues for three scales of TAI.

Table 4

Factor Analysis Results for the TAI

\begin{tabular}{lccc}
\hline Item & TAI-Total & TAI-Worry & TAI-Emotionality \\
\hline 1 & 0.36 & & \\
12 & 0.48 & & \\
13 & 0.49 & & \\
19 & 0.46 & 0.49 & \\
3 & & 0.55 & \\
4 & & 0.46 & \\
5 & & 0.43 & \\
6 & & 0.44 & \\
7 & & 0.45 & \\
14 & & 0.45 & \\
17 & 0.50 & \\
20 & & & 0.39 \\
2 & & & 0.50 \\
8 & & & 0.38 \\
9 & & & 0.45 \\
10 & & & 0.56 \\
11 & & & 0.71 \\
15 & & 6.01 & 5.49 \\
16 & 8.48 & 1.56 & 1.45 \\
18 & 2.21 & &
\end{tabular}

Table 4 shows that the percentage of variance was $8.48 \%$ for Test Anxiety Inventory- Total, $6.01 \%$ for Test Anxiety Inventory- Worry, and $5.6 \%$ for Test Anxiety Inventory- Emotionality. Similarly, the eigenvalues for three scales of Test Anxiety Inventory ranged from 1.45 to 2.21. Overall, the various analyses expressed in Table 4 supported a strong structure for 20 items with three scales of Test Anxiety Inventory. 


\subsection{Internal Consistency Reliability for Test Anxiety Inventory}

According to Eccles (2007), "the internal consistency reliability of any scale is a measure of the extent to which items within the same scale assess the same construct" (p. 69) ${ }^{|52|}$. After the factor analysis, internal consistency reliability for Test Anxiety Inventory was conducted. Table 5 below shows the internal consistency reliability of each scale of TAI.

Table 5

Internal Consistency Reliability (Cronbach Alpha Coefficient) for Two Units of Analysis for TAI

\begin{tabular}{|c|c|c|c|}
\hline Scales & $\begin{array}{l}\text { No. of } \\
\text { Items }\end{array}$ & $\begin{array}{l}\text { Units of } \\
\text { Analysis }\end{array}$ & $\begin{array}{c}\text { Alpha } \\
\text { Reliability }\end{array}$ \\
\hline \multirow[t]{2}{*}{ TAI- Total } & 4 & Individual & 0.66 \\
\hline & & Class Mean & 0.71 \\
\hline \multirow[t]{2}{*}{ TAI- Worry } & 8 & Individual & 0.73 \\
\hline & & Class Mean & 0.79 \\
\hline \multirow[t]{2}{*}{ TAI- Emotionality } & 8 & Individual & 0.81 \\
\hline & & Class Mean & 0.88 \\
\hline
\end{tabular}

Sample consisted of 2,145 students.

Table 5 shows that alpha reliability of different scales of TAI ranged from 0.66 to 0.81 with the individual student as the unit of analysis and from 0.71 to 0.88 with the class as the unit of analysis. The results of Table 5 express that TAI has satisfactory internal consistency reliability when used with $10^{\text {th }}$ grade science students in the Punjab province.

\subsection{Discriminant Validity for TAI}

Discriminant validity for TAI was also measured by using the mean correlations of the scale with other scales. Table 6 below shows the discriminant validity (mean correlation with other scales) with two units of analysis for three scales of Test Anxiety Inventory (TAI).

Table 6

Discriminant Validity (Mean Correlation with other Scales) for Two Units of Analysis for three scales of TAI

\begin{tabular}{lccc}
\hline Scales & $\begin{array}{c}\text { No. of } \\
\text { Items }\end{array}$ & $\begin{array}{c}\text { Units of } \\
\text { Analysis }\end{array}$ & $\begin{array}{c}\text { Mean Correlation } \\
\text { with Other Scales }\end{array}$ \\
\hline TAI- Total & 4 & Individual & 0.19 \\
& & Class Mean & 0.27 \\
TAI- Worry & 8 & Individual & 0.22 \\
& & Class Mean & 0.29 \\
TAI- Emotionality & 8 & Individual & 0.32 \\
& & Class Mean & 0.40 \\
\hline
\end{tabular}

Sample consisted of 2,145 students.

Table 6 shows that discriminant validity of an individual student as unit of analysis ranged from 0.19 to 0.32 for three scales of TAI. Similarly, the discriminant validity for class as unit of analysis ranged from 0.27 to 0.40 for these scales TAI. The results indicated that raw scores on scales of TAI are highly independent at individual level, but these scales overlap at class mean as unit of analysis.

\subsection{Ability of TAI to Differentiate between Classrooms}

For evidence of validity, one-way Analysis of Variance (ANOVA) was used to check whether all scales Test Anxiety Inventory (TAI) were able for significant differentiation between perceptions of students in different classes. Table 7 below shows the internal consistency reliability ANOVA results for two units of analysis for three scales of TAI.

Table 7

Internal Consistency Reliability (Cronbach Alpha Coefficient) and Ability to Differentiate between Classrooms (ANOVA Results) for Two Units of Analysis for TAI

\begin{tabular}{|c|c|c|c|c|}
\hline Scales & $\begin{array}{l}\text { No. of } \\
\text { Items }\end{array}$ & $\begin{array}{l}\text { Units of } \\
\text { Analysis }\end{array}$ & $\begin{array}{c}\text { Alpha } \\
\text { Reliability }\end{array}$ & $\begin{array}{c}\text { ANOVA } \\
\text { Eta }^{2}\end{array}$ \\
\hline TAI- Total & 4 & $\begin{array}{l}\text { Individual } \\
\text { Class Mean }\end{array}$ & $\begin{array}{l}0.66 \\
0.71\end{array}$ & $0.10 * * *$ \\
\hline TAI- Worry & 8 & $\begin{array}{l}\text { Individual } \\
\text { Class Mean }\end{array}$ & $\begin{array}{l}0.73 \\
0.79\end{array}$ & $0.11 * * *$ \\
\hline TAI- Emotionality & 8 & $\begin{array}{l}\text { Individual } \\
\text { Class Mean }\end{array}$ & $\begin{array}{l}0.81 \\
0.88 \\
\end{array}$ & $0.09 * * *$ \\
\hline
\end{tabular}


Table 7 shows that each scale of TAI differentiate significantly $(\mathrm{p}<0.001)$ between classrooms for all the students. The value of $\mathrm{Eta}^{2}$ ranges from 0.09 to 0.11 for the $10^{\text {th }}$ grade science students. The data for alpha reliability and $\mathrm{Eta}^{2}$ presented in Table 7 indicates that all three scales of TAI are valid and reliable for the measurement of students' test anxiety. So, researchers can use this Urdu version of Test Anxiety Inventory (TAI).

\section{Discussion}

The findings from internal consistency reliability (Cronbach alpha coefficient) and discriminant validity in the present study have confirmed that Urdu version of Test Anxiety Inventory (TAI) is found to be valid and reliable.

Spielberger (1980) ${ }^{|14|}$ validated the instrument of Test Anxiety Inventory (TAI) on high school, college and graduate level students. According to him, the value of alpha reliability coefficient was 0.81 . In the present study, this value for Urdu version of TAI was calculated as 0.893 in the pilot study. In some other studies, TAI was also validated and the values of alpha reliabilities were in resemblance or slightly different to the values of present study (Ali, 2012 ${ }^{|46|}$; Lufi \& Darliuk, $200{ }^{|42|}$; Hong, $1999^{|39|}$; Shermis \& Lombard, $1998^{|38|}$; Williams, $1992^{|34|}$; Sharma \& Sud, $1990^{|19|}$; and Schwarzer, $1980^{|28|}$ ). In the final study, on the other hand, alpha reliability values of different scales of TAI (TAI-Total, TAI-Worry, and TAI-Emotionality) ranged from 0.66 to 0.81 with the individual student as the unit of analysis and from 0.71 to 0.88 with the class as the unit of analysis. Similarly, the discriminant validity of an individual student as unit of analysis ranged from 0.19 to 0.32 for three scales of TAI and the discriminant validity for class as unit of analysis ranged from 0.27 to 0.40 for these scales TAI.

All the values of alpha reliability and discriminant validity in this study replicated the results of previous research studies and made it clear that the instrument of Test Anxiety Inventory (TAI) was valid and reliable when used in Pakistani context among $10^{\text {th }}$ grade science students of Punjab province.

At the end, it is suggested that the same research or any other research similar to this one can be conducted on all levels i.e., from primary level up to university level. Similarly, this research may also be conducted on students taking subjects of arts. So, its results can be generalized for whole of the population including students of science as well as arts.

\section{References}

[1] Phillips, B. N., Martin, R. P., \& Myers, J. (1972). Interventions in relation to anxiety in school. In C. D. Spielberger (Ed.). Anxiety: Current trends in theory and research (Vol. 2). New York: Academic Press.

[2] Sarason, I. G. (1984). Stress, anxiety and cognitive interferences: Reactions to tests. Journal of Abnormal and Social Psychology, 46, 929-938.

[3] Cohen, A., Yaakobi, D., Porat, A. B., \& Chayoth, R. (1989). The effects of biology games on students' anxiety and in their achievement. International Journal of Science Education, 11(4), 387-394.

[4] Reber, R. S. (1995). The Penguin Dictionary of Psychology. (2 $2^{\text {nd }}$ ed.). London: Penguin.

[5] Lufi, D., Okasha, S., \& Cohen, A. (2004). Test anxiety and its effect on the personality of students with learning disabilities. Learning Disability Quarterly, 27(3), 176-184.

[6] Spielberger, C. D. (1979). Understanding stress and anxiety. New York: Harper \& Row.

[7] Sarason, I. G., \& Stoops, R. (1978). Test anxiety and the passage of time. Journal of Consulting and Clinical Psychology, 46, 102109.

[8] Duesek, J. B. (1980). The development of test anxiety in children. In I. G. Sarason (Ed.). Test anxiety: Theory, research, and applications (pp. 87-110). Hillsdale, NJ: Erlbaum.

[9] Sarason, I. G. (1984). Stress, anxiety and cognitive interferences: Reactions to tests. Journal of Abnormal and Social Psychology, 46, 929-938.

[10] Liepmann, D., Marggraf, C., Felfe, J., \& Hosemann, A. (1992). Anxiety, action orientation, subjective state and situational aspects: A study of tank-lorry drivers. In K. Hagtvet \& T. B. Johnson (Eds.). Advances in test anxiety research (Vol. 7, pp. 130-141). Amsterdam/Lisse, The Netherlands: Swets \& Zeitlinger.

[11] Spielberger, C. D., \& Vagg, P. R. (1995). Test anxiety: A transactional process model. In C. D. Spielberger \& P. R. Vagg (Eds.). Test anxiety: Theory, assessment, and treatment (pp. 3-14). Washington, DC: Taylor \& Francis.

[12] Zeidner, M. (1998). Test anxiety: The state of the art. New York: Plenum Press.

[13] Hong, E. (1998). Differential stability of individual differences in state and trait anxiety. Learning and Individual Differences, 10, 5169.

[14] Spielberger, C. D. (1980). Test Anxiety Inventory: Preliminary Professional Manual. Palo Alto, CA: Consulting Psychologists Press.

[15] Sapp, M., Durand, H., \& Farrel, W. (1995). The effects of mathematics, reading and writing tests in producing worry and emotionality test anxiety with economically and educationally disadvantaged college students. College Students Journal, 29(1), 122125 .

[16] Liebert, R. M., \& Morris, C. W. (1969). Cognitive and emotional components of test anxiety: A distinction and some initial data. Psychological Reports, 20, 975-978.

[17] Unruh, S. M. \& Lowe, P. A. (2010). The development and validation of a Spanish language version of the test anxiety inventory for children and adolescents. Hispanic Journal of Behavioral Sciences, 32(1), 164-183.

[18] Morris, L. W., Davis, M. A., \& Hutchings, C. H. (1981). Cognitive and emotional components of test anxiety: Literature review and revised Worry-Emotionality Scale. Journal of Educational Psychology, 73, 541-555.

[19] Sharma, S., \& Sud, A. (1990). Examination stress and test anxiety: Across-cultural perspective. Psychology \& Developing Societies, 2, 183-201.

[20] Mandler, G., \& Sarason, S. B. (1952). Some correlates of test anxiety. Journal of Abnormal and Social Psychology, 47, 810-817. 
[21] Sarason, I. G. (1958). Interrelationships among individual difference variables, behavior in psychology, and verbal conditioning. Journal of Abnormal and Social Psychology, 56, 339-344.

[22] Alpert, R., \& Haber, R. N. (1960). Anxiety in academic achievement situations. Journal of abnormal and Social Psychology, 61, 207215.

[23] Suinn, R. M. (1969). The STABS, a measure of test anxiety for behavior therapy: Normative data. Behavior Research and Therapy, 7, 335-339.

[24] Osterhouse, R. A. (1970). Desensitization and study skills as treatment for two types of test-anxious students. Journal of Counseling Psychology, 19, 301-307.

[25] Lowe, P. A., \& Lee, S. W. (2004). Test Anxiety Inventory for Children and Adolescents. Lawrence, KS: University of Kansas.

[26] Chapell, M. S., Blanding, B., Silverstein, M. E., Takahashi, M., Newman, B., Gubi, A., \& McCann, N. (2005). Test anxiety and academic performance in undergraduate and graduate students. Journal of Educational Psychology, 97(2), $268-274$.

[27] Spielberger, C. D., Gonzalez, H. P., Taylor, C. J., Algaze, B., \& Anton, W. D. (1978). Examination stress and test anxiety. In C. D. Spielberger \& I. G. Sarason (Eds.). Stress and Anxiety (Vol. 5). New York: Hemisphere/Wiley.

[28] Schwarzer, R. (1980). Worry and emotionality as separate components in test anxiety. Retrieved on November 10,2010 from http://www.eric.ed.gov/ERICWebPortal/Search/ED202903.

[29] Bentler, P. M. (1980). Multivariate analysis with latent variables: Causal modeling. Annual Review of Psychology, 31, 419-456.

[30] Anthony, J., Devito, Tryon, G. S., \& Kane, A. (1983, April). Validation of TAI using items of the Mooney Problem Checklists. Paper presented at a symposium of the annual meeting of Eastern Psychological Association, Philadelphia, Pennysylvania. Retrieved on November 10, 2010 from http://www.eric.ed.gov/ERICWebPortal/Search/ED250336.

[31] McAuliffe, E. A., Trueblood, C. R. (1986, April). Factor analysis: A tool for studying mathematics anxiety. Paper presented at a symposium of the annual meeting of American Educational Research Association, San Francisco, USA. Retrieved on November 10, 2010 from http://www.eric.ed.gov/ERICWebPortal/Search/ED 270497.

[32] Rocklin, T. (1989, March). Individual differences in computerized self-adapted testing. Paper presented at a symposium of the annual meeting of American Educational Research Association, San Francisco, USA. Retrieved on November 10 , 2010 from http://www.eric.ed.gov/ERICWebPortal/Search/ED 310136.

[33] Wynstra, S., \& Cummings, C. (1990). Science anxiety: Relation with gender, year in chemistry class, achievement, and test anxiety. Paper presented at the annual meeting of the Midwestern Educational Research Association, Chicago, USA. Retrieved on November 10, 2010 from http://www.eric.ed.gov/ERICWebPortal/Search/ED 331837.

[34] Williams, J. E. (1992). Effects of test anxiety and self-concept on performance across curricular areas. Retrieved on November 10, 2010 from http://www.eric.ed.gov/ERICWebPortal/Search/ED 344903.

[35] Calvo, M. G., \& Carreiras, M. (1993). Selective influence of test anxiety on reading processes. British Journal of Psychology, 84, 375-388.

[36] Spielberger, C. D., \& Diaz-Guerrero, R. (1975). State-Trait Anxiety Inventory: Manual and Instructions. Mexico: El Manual Moderno.

[37] Stallworth-Clark, R., Cochran, J., \& Scott, J.S. (1998, November). Test anxiety and effect of anxiety-reduction training of students' performance on the Georgia Regents Reading exams. Paper presented at the annual meeting of Georgia Educational Research Association, Atlanta, GA. Retrieved on November 10, 2010 from http://www.eric.ed.gov/ERICWebPortal/Search/ED 428092.

[38] Shermis, M. D., \& Lombard, D. (1998). Effects of computer-based test administrations on test anxiety and performance. Computer in Human Behavior, 14(1), 111-123.

[39] Hong, E. (1999). Test anxiety, perceived test anxiety, and test performance: Temporal patterns of their effects. Learning and Individual Differences, 11(4), 431-447.

[40] Maxfield, L., \& Melnyk, W. T. (2000). Single session treatment of test anxiety with eye movement desensitization and processing (EMDR). International Journal of Stress Management, 7, 87-101.

[41] Kaya, A. (2004). Test anxiety and psychopathology in fifth-grade students in Turkey. International Journal of Educational Reform, 13(1), 19-26

[42] Lufi, D., \& Darliuk, L. (2005). The interactive effect of test anxiety and learning disabilities among adolescents. International Journal of Educational Research, 43, 236-249.

[43] Putwain, D. W. (2007). Test anxiety in UK school children: Prevalence and demographic patterns. British Journal of Educational Psychology, 77, 579-593.

[44] Putwain, D. W. (2008). Test anxiety and GCSE performance: The effect of gender and socio-economic background. Educational Psychology in Practice, 24(4), 319-334.

[45] Nicholson, A. M. (2010). Effects of test anxiety on student achievement (ACT) for college bound students. Dissertation Abstracts International, 70(7), pp. 2400.

[46] Ali, M. S. (2012). Establishing the construct validity and reliability of an Urdu translation of the Test Anxiety Inventory. The Assessment Handbook, 9, 15-26.

[47] Dunn-Rankin, P. (1983). Scaling Methods. London: Lawrence Erlbaum Associates.

[48] Nunnally, J. C., \& Bernstein, I. H. (1994). Psychometric theory. (3 ${ }^{\text {rd }}$ Ed.). New York: McGraw Hill.

[49] Zaman, D. A. (2011). Relationship between mathematical thinking and achievement in mathematics among secondary school students of North West Frontier Province, Pakistan (Doctoral Thesis). Islamabad: International Islamic University.

[50] Kaiser, H. F. (1960). The application of electronic computers to factor analysis. Educational and Psychological Measurement, 20, 141-150.

[51] Nelson, L. R. (2005). Some observations on the Screen test, and on coefficient alpha. Thai Journal of Educational Research and Measurement (ISSN 1685-6740): 3 (1), 1-17.

[52] Eccles, L. (2007). Gender differences in teacher-student interactions, attitudes and achievement in middle school science (Doctoral Thesis). Western Australia: Science and Mathematics Education Centre, Curtin University of Technology. 